\title{
Cien años en lucha constitucional por la libertad de enseñanza religiosa en las escuelas: la Unión Nacional de Padres de Familia 1917-2017
}

\author{
A Hundred Years of Constitutional \\ Struggle for the Freedom of Religious Teaching \\ in Schools: The National Union of Parents
}

\section{Valentina Torres Septién Torres}

Universidad Iberoamericana valentinatorresseptien@gmail.com

\begin{abstract}
Resumen
Durante el Congreso Constituyente de 1917, los católicos mexicanos estuvieron a la expectativa de la redacción de algunos artículos que implicaban a la Iglesia católica. Uno de éstos, el más polémico, fue el artículo $3^{\circ}$, cuya redacción y promulgación no estuvo exenta de numerosas intervenciones y reclamos, tanto de la jerarquía católica como de los laicos. Este trabajo aborda el papel que desempeñó la Unión Nacional de Padres de Familia (UNPF), organización laica, paraeclesial, actor externo al grupo dominante y cuyo objetivo fue luchar por obtener la libertad de enseñanza, entendida en ese momento como la libertad para enseñar religión en las escuelas. Reconocía "obediencia absoluta" a las autoridades eclesiásticas, con quien mantendría ligas muy estrechas. Sus miembros eran católicos beligerantes, en su mayoría abogados. Desde sus inicios, defendió el respeto a la familia como base indispensable de la convivencia social, el derecho de los padres de familia para elegir la educación de sus hijos, así como la libertad de enseñanza, entendida como la oposición al laicismo oficial. La lucha por la libertad de enseñanza se convirtió en su principal motivación; derogar el laicismo era el medio para alcanzar esta libertad.
\end{abstract}

Palabras clave: Unión Nacional de Padres de Familia, Iglesia católica, libertad de enseñanza, México

\section{Abstract}

During the Constitutional Assembly of 1917, Mexican Catholics were expectant about the introduction of some articles involving the Catholic Church. One of them, the more controversial, was article $3^{\text {rd }}$, the 
drafting and enactment of which was not exempt from numerous interventions and claims, both from the Catholic hierarchy and the laity. This paper addresses the role that played the National Union of Parents (UNPF), secular, paraeclesial organization, external to the dominant group actor and whose objective was to fight for the freedom of education, understood as the freedom to teach religion in the schools. It recognized the ecclesiastical authorities who maintain very close links and "absolute obedience". Its members were Catholic belligerents, mostly lawyers. Since its beginning, it defended the respect to the family as the essential basis of social coexistence, the right of parents to choose their children's education, as well as freedom of education, understood as the opposition to official secularism. The struggle for freedom of education became his main motivation; repeal the secularism was the way to achieve this freedom

Keywords: National Union of Parents, Catholic Church, freedom of teaching, Mexico

\section{Introducción ${ }^{1}$}

Desde su llegada con los españoles a las nuevas colonias americanas, la Iglesia católica tenía la prioridad de evangelizar a los grupos de nativos. Para ello, y como parte de sus objetivos, los misioneros se dedicaron a la enseñanza de la lectura y la escritura, para que los candidatos a nuevos cristianos aprendieran la nueva doctrina y las enseñanzas evangélicas. Por ello, y por delegación del mismo rey de España, los religiosos fueron los primeros educadores en la América española, actividad que realizarían junto con el Estado durante los tres siglos que duró el virreinato.

A partir del siglo XIX, las nuevas condiciones del Estado independiente cambiaron la composición de fuerzas. El Estado mexicano se adjudicó la necesidad y responsabilidad de formar a los nuevos ciudadanos. Este cambio tan fundamental modificó paulatinamente el desempeño de la Iglesia católica en los territorios independizados. Sin embargo, en la tradición y doctrina de la Iglesia, seguía vigente la necesidad de formar y cristianizar a los pueblos.

A partir de la segunda mitad del siglo XIX, con la guerra de Reforma, las leyes emanadas en la nueva Constitución (1857) y las posteriores leyes que reglamentaron y limitaron la acción social de la Iglesia, se iniciaba una lucha entre las dos potestades, la cual eclosionaría en la primera mitad del siglo Xx. La disputa se acrecentó por las orientaciones vaticanas que generaron una forma nueva de organización de su sistema institucional, al que se llamó catolicismo social.

Esta moderna forma en que la Iglesia se acercaba a los problemas sociales actualizó sistemas de acción para la Iglesia, que en México impulsó una serie de disposiciones encaminadas

\footnotetext{
${ }^{1}$ Algunas ideas de esta investigación fueron publicadas en Torres (1997).
} 
a recuperar los espacios de poder que la institución católica había visto limitada por el Estado. La fuerza de estas acciones tuvo su sustento en la encíclica de León XIII Rerum Novarum ("De las cosas nuevas", 1891). A raíz de la aparición de esa encíclica, el catolicismo social, alternativa que presentaba el papa frente al temido liberalismo y al socialismo que empezaba a extenderse por Europa, tuvo un fuerte impacto en organizaciones y grupos católicos, como bien lo ha explicado Manuel Ceballos (1991) en sus trabajos referentes a esa época.

El porfiriato (1880-1910) propició un optimismo en el desarrollo económico de México y la confianza en un futuro de progreso, que bien se identificaba con la idea liberal de un país moderno. El régimen de Porfirio Díaz en su clara postura de mantener "la paz", trató de buscar una alianza con la jerarquía eclesiástica, con base en una política de aparente condescendencia y tolerancia, aunque esto no implicó el reconocimiento o aceptación de un estado confesional por parte del Estado. Lo anterior propició que la Iglesia se fortaleciera a través de la fundación de congregaciones religiosas e iniciativas educativas. En los años del porfiriato, la Iglesia y el Estado mantuvieron la confrontación iniciada en el siglo xIX por el poder sobre la orientación y dirección de la educación. Los liberales continuaron sus esfuerzos para evitar que ésta siguiera en manos de la Iglesia, pero la tolerancia de don Porfirio le concedió una posición de privilegio.

Sin embargo, la revolución mexicana trajo consigo infinidad de cambios en las instituciones, los proyectos de Estado y en general en la vida del país. Al triunfo de los liberales, Venustiano Carranza, jefe supremo de la nación en 1916, percibió la necesidad de dar un sustento legal a su gobierno y convocó a un congreso constituyente.

\section{La lucha contra el laicismo}

Los debates dados en torno al artículo $3^{\circ}$, desde 1857 y concretamente al concepto de laicismo, muestran la diversidad de posturas existentes en el momento. ¿Qué era para los ideólogos constitucionalistas el laicismo educativo, y cuál era la definición que de éste daban los católicos? Si bien se le puede definir como la exclusión de toda doctrina religiosa —en este caso para la educación-, tanto para los congresistas, como para la lglesia y quienes detractaron la redacción del artículo $3^{\circ}$ significaban cuestiones muy distintas.

En primer término, la Iglesia consideraba al laicismo como un error. Ya Pío IX, en 1864, lo había condenado en su encíclica Quanta Cura y en el Syllabus. La Iglesia católica señalaba, sin lugar a dudas, que el fin único de la educación católica era la formación del individuo, con vistas a un fin trascendente: la salvación de su alma. La escuela debía ser un medio para alcanzar este propósito. 
Posteriormente, en la encíclica Divini illius magistri del papa Pío XI fijó claramente el objetivo de la educación católica:

puesto que la educación esencialmente consiste en la formación del hombre cual debe ser y como debe portarse en la vida terrena para conseguir el fin sublime para el que fue creado, es evidente que, como no puede existir educación verdadera que no esté totalmente ordenada al fin último, así [... no puede existir educación completa y perfecta si la educación no es cristiana (Pío XI, 1935: 7).

Este axioma era el que había tomado la Iglesia y sus organizaciones para defender su postura frente a la educación laica en 1917, y posteriormente a lo largo de todo el siglo Xx. En el documento citado, para la Iglesia, las tres entidades responsables de impartir educación eran la Iglesia, la familia y el Estado, en ese orden. El derecho de la familia era anterior al de la sociedad y al del Estado, e inviolable por parte de las potestades terrenales, e incluía no sólo la educación moral y religiosa, sino también la física e intelectual. Al Estado le tocaba proteger con sus leyes los derechos, tanto de la familia como de la Iglesia, para impartir educación cristiana, y sólo debía suplir a los padres cuando éstos estuvieran incapacitados para realizar dicha función. Le cedían el privilegio de la enseñanza cívica relativa al bien común, que no se oponía a la doctrina de la Iglesia, pero obviaban el que el Estado definiera los parámetros educativos. Sólo teniendo en cuenta estos principios es como se entiende la fuerte oposición que la Iglesia ejerció (y ejerce) sobre el laicismo. Por ello, en México, el laicismo ha sido, sobre todo, una militancia antirreligiosa (o por lo menos anticlerical) (Olimón, 2011: 8), y en términos educativos ésta no se concibe sin valores, sin la ideología propia del cristianismo.

Por su parte, los congresistas percibían la laicidad de tres maneras: como independencia de los poderes Ejecutivo, Legislativo y Judicial frente a las autoridades religiosas; como la neutralidad de los órganos estatales o como garantía de la libertad religiosa, comprendida en todas sus dimensiones y no únicamente como libertad de culto u opción negativa o positiva frente a convicciones religiosas o filosóficas (Olimón, 2011: 8)

En relación con la redacción del artículo $3^{\circ}$, Venustiano Carranza presentó un proyecto conservador que no agradó a la mayoría parlamentaria, constituida fundamentalmente por el nuevo sector liberal triunfante, que buscaba una trasformación sobre todo en los ámbitos económico y social. El proyecto carrancista proclamaba que la enseñanza elemental y superior sería laica y gratuita en los establecimientos oficiales donde fuese impartida. Este artículo sostenía el laicismo sólo para las escuelas dependientes del gobierno; las instituciones particulares quedaban en entera libertad de acción y el Estado no tenía derecho de intervenir en sus políticas educativas. Esta redacción favorecía, sin duda, a los católicos y a sus escuelas, 
pues les permitía buenos espacios de funcionamiento. El proyecto de artículo señalaba: "Habrá plena libertad de enseñanza, pero será laica la que se dé en los establecimientos oficiales de educación y gratuita la enseñanza primaria y elemental que se imparta en los mismos establecimientos" (González, 1960: 320).

Sin embargo, la iniciativa carrancista no fue aceptada por el Constituyente, que buscaba un cambio sustancial, sobre todo en lo relativo a cuestiones religiosas; el grupo más radical debatió ampliamente la redacción del artículo. Para los más radicales, la Iglesia sustituía funciones que correspondían al Estado desde el porfiriato, en el centro y norte del país, en áreas como salud, educación, organizaciones sociales o políticas. Y precisamente porque el Estado no podía cumplir con muchas de esas funciones, éstas fueron asumidas por la Iglesia, que funcionaba como un "paraEstado". No se trataba de enfrentar a la Iglesia como institución, sino las funciones que ésta realizaba. "Era la construcción de un enemigo [...]. El gran enemigo de la Revolución mexicana, que para muchos era la Iglesia" (Rodríguez, en curso).

La discusión del artículo $3^{\circ}$ dejaba clara la posición que los revolucionarios, sobre todo los más jacobinos, tomarían respecto de la Iglesia. En las discusiones se manejaron argumentos en los que se le acusaba de ser "el enemigo más cruel y tenaz de nuestras libertades"; sus "miedos" frente a la Iglesia se hacían evidentes al decir que "la tendencia manifiesta del clero a subyugar la enseñanza no es sino un medio preparatorio para usurpar las funciones del Estado" (Diario de los debates del Congreso Constituyente, 1960: 542).

La idea de neutralidad tampoco prosperó. Al respecto, Pablo Latapí señala que la posibilidad de este deslindamiento no era viable, en tanto que el Estado, "al elaborar sus programas e imprimirles sus valores, se decantan hacia una postura, $u$ otra, haciendo imposible la neutralidad absoluta" (Latapí, 2000: 42).

En relación con la libertad de enseñanza "absoluta" (Adame, 1992: 13), la imposibilidad de formar generaciones renovadas, pues la Iglesia mantendría la herencia del fanatismo, que devendría en nuevas "contiendas" sangrientas (Diario de los debates del Congreso Constituyente, 1960: 643). Otros diputados, como Alfonso Cravioto, tomaron posturas más radicales al señalar que no sólo debía arrebatárseles a los padres el derecho de escoger el tipo de educación de sus hijos, sino que se debía penetrar en los hogares para evitar que los padres enseñaran errores religiosos (Diario de los debates del Congreso Constituyente, 1960: 662).

Los moderados, como Félix Palavicini, señalaban la inconveniencia de atentar contra las garantías individuales, y José Natividad Macías consideraba como "barbaridad" quitar ese derecho al pueblo (Diario de los debates del Congreso Constituyente, 1960: 701). Al final, la comisión dictaminó el proyecto de redacción y afirmó que la enseñanza religiosa, con ideas abstractas, no podía ser asimilada por los niños y contribuía a "contrariar el desarrollo psicológico natural del niño y tiende a producir cierta deformación de su espíritu [sic]" (Diario de los debates del Congreso Constituyente, 1960: 633). 
En este sentido, la Constitución entraba en contradicción al coartar la libertad, bandera que tomarían los católicos para defenderse frente a un artículo que consideraron violatorio de este derecho. El laicismo quedó definitivamente instaurado, haciendo posible un proceso de secularización que iría transformando "los sistemas simbólicos integradores de la sociedad [...] y será una forma de secularización con un campo rico de expresiones e interacciones al interior de la educación" (García, 1996: 440).

La comisión encargada de la redacción del artículo $3^{\circ}$ propuso extender el laicismo a las escuelas particulares de educación primaria, así como prohibir a miembros de asociaciones religiosas establecer, dirigir o impartir enseñanza en los colegios; con los artículos $4^{\circ}, 24^{\circ}, 27^{\circ}$ y $130^{\circ}$ se facultó a las legislaturas estatales para determinar, según las necesidades, el número máximo de ministros de culto en cada estado; prohibió los actos de culto público fuera de los templos y proscribió los votos religiosos y las órdenes monásticas. (Sánchez, 1992: 8). Ramón Sánchez Medal, presidente de la Unión Nacional de Padres de Familia (UNPF) considera que "Fue así como la Constitución de 1917 cambió radicalmente el régimen de separación o independencia entre el Estado y la Iglesia católica, para implantar en su lugar el avasallamiento de la Iglesia católica por el Estado [...]" (Sánchez, 1992: 8).

La libertad de enseñanza, entendida a la manera constitucionalista, es decir, la educación laica en torno de la cual se dieron las mayores disputas, fue la manera como el Estado ejerció "democráticamente" un fuerte control ideológico, aniquilando a su contendiente por el poder educativo. La orientación revolucionaria de la educación debería impedir la penetración de ideas religiosas.

Los constituyentes pensaban que con el artículo $3^{\circ}$ destruirían la escuela católica, ese elemento tan importante para mantener vivo el espíritu de la Iglesia. El propósito del Estado "era el de controlar a la Iglesia de manera que no le pudiera disputar el poder mediante el ejercicio de actividades religiosas o parapolíticas, que de hecho la colocaron en un real ejercicio de la soberanía eclesiástica en disputa con la soberanía del Estado" (Christlieb, 1962: 12-15).

\section{La UNPF y su resistencia al artículo $3^{\circ}$}

La Iglesia, jurídicamente incapacitada para evitar esta decisión amparada en conceptos supuestamente democráticos y legales, se encontró ante una situación de subordinación y desventaja que debió enfrentar para mantenerse vigente en el terreno educativo. Afortunadamente para aquélla, el Estado dejó un reducto por donde pudo continuar su obra educativa. El artículo $3^{\circ}$ no limitó la participación de los miembros de sociedades religiosas en su calidad de maestros. La prohibición consistió en que corporaciones o ministros religiosos dirigieran o establecieran instituciones educativas. Sin embargo, esto último podía solucionarse 
mediante ingeniosas maniobras, como crear sociedades de carácter civil, para acreditar que los maestros no fueran ni religiosos ni extranjeros como lo exigía la ley.

El revuelo que causó el artículo $3^{\circ}$ entre los miembros de la Iglesia y sus organizaciones fue inmediato. Estas últimas afirmando no tener un vínculo directo con la jerarquía, se unieron con el objetivo de instaurar el orden social cristiano desde una plataforma laica. El clero, desde el exilio y a través del arzobispo de Mexico, José Mora y del Río, y de los obispos exiliados, manifestaron su inconformidad y exhortaron a los "pueblos civilizados de la Tierra" a luchar por la libertad de enseñanza. A partir de ese momento, señalaron a la revolución como un movimiento político, que se había convertido en "arreligioso" (Rius, 1963: 104). Según Robert Quirk (1986: 100), los obispos negaban querer mezclarse en asuntos políticos, sin embargo, sostenían que no podían aceptar una Constitución tan palpablemente contraria a la ley de Dios. Condenaban una rebelión armada contra la autoridad legalmente constituida, pero afirmaban que trabajarían dentro de la ley, utilizando cualquier medio legal para cambiar las leyes existentes que regulaban las relaciones entre la Iglesia y el gobierno mexicano.

La Constitución afectó jurídica y políticamente el destino de la Iglesia, al adjudicar al Estado el control de la educación y de otras instancias. El Estado asumía a la Iglesia como una institución política y no daba validez a su función religiosa. Ante el menoscabo de su posible acción participativa, la Iglesia, como contendiente por el poder, se alió a un grupo social integrado por católicos militantes, pertenecientes a las esferas de profesionistas e intelectuales de las clases media y alta, y juntas lucharon por recuperar el poder y los privilegios perdidos.

Algunos padres de familia informados de las intenciones del Congreso buscaron la forma de impedir la incorporación del nuevo artículo. Inmediatamente empezaron a organizarse; tal fue el caso de la Unión de Madres Católicas de Monterrey, quienes enviaron un memorial al Congreso en protesta por las leyes "vejatorias y opresoras de nuestra santa religión" (Rius, 1963: 114). Hicieron hincapié en que la "instrucción laica, racional o como quiera llamársele, es una educación atea, impía" (Rius, 1963: 114).

Por otra parte, la Sociedad Mexicana contra la Violación de la Libertad de Enseñanza, que vinculaba a padres de familia, insistió ante el Constituyente sobre sus derechos en materia educativa, es decir, la facultad para decidir el tipo de educación que deseaban para sus hijos. De esta forma, se iniciaba una polémica rabiosa, que desembocaría finalmente en la guerra cristera.

En este contexto surgirá un nuevo grupo cohesionado, que tendrá una forma importante de participación social. Por vez primera, los padres de familia se constituirán en una fuerza de acción política, social y religiosa, en torno a las acciones educativas de las cuales habían estado relegados. Los progenitores serán actores importantes y su organización 
tendrá una función paraeclesial y unificadora, cuyos objetivos se centraron en "lo educativo", aunque también en otras acciones que trascendieron este primer objetivo.

El propósito de la UNPF fue derogar, o en su defecto reformar, el artículo $3^{\circ}$ constitucional, para establecer lo que en ese momento sus miembros consideraban como la libertad de enseñanza, esto es, la posibilidad de enseñar religión (católica), tanto en las escuelas públicas como en las privadas. La nueva organización estaba orientada a la salvaguarda de la educación católica y también se inspiró en la encíclica Rerum Novarum. Así lo reconocen sus miembros: "los antecedentes remotos de la UNPF los encontramos en aquellas generaciones de católicos que, respondiendo al Ilamado del papa León XIII [...] se comprometieron a participar en la solución de la cuestión social" (Pérez, 2019: 31).

La UNPF se constituyó por padres de familia de todo el país, fundamentalmente pertenecientes a la antigua burguesía porfirista y a la clase media. Fue la primera organización de padres de escuelas particulares, de las muchas que se formarían posteriormente. Se estableció como una asociación civil, organismo paraeclesial que reconocía "obediencia absoluta a las autoridades eclesiásticas", con quienes mantuvo ligas muy estrechas, aunque no manifiestas, por el temor existente a que sus acciones comprometieran a la Iglesia en algún momento; posteriormente, defendería una postura más radical que aquélla. Constituida básicamente por abogados, se estableció el 27 de abril de 1917. Inicialmente llamada Asociación Nacional de Padres de Familia, luchó contra el laicismo y la abrogación del artículo 3², que se convirtió en su principal bandera, esgrimida a todo lo largo del siglo Xx. Otros de sus objetivos consistieron en "proponer y adoptar los mejores métodos educativos; advertir a las autoridades sobre la intromisión de la antirreligiosidad y el sectarismo en las escuelas públicas, y vigilar la moralidad de la enseñanza [...]”3 (Pérez, 2010: 389).

Utilizando un lenguaje que calificaba posturas ideológicas, la Unión señaló a la escuela oficial como "enemiga pública de la paz y de la familia" y causante de los efectos nefastos que la educación producía en la formación de los niños al volverlos "malvados y perversos" (González, 1921-1922: 117). Asimismo, consideraba que las escuelas laicas "pervierten la inteligencia y corrompen los corazones" y "tienen que producir necesariamente los frutos amarguísimos de hombres nocivos a la sociedad y para los gobiernos" (González, 1921-1922: 22).

\footnotetext{
2 Fue firmada por Benjamín Anguiano, Rafael de la Mora, Manuel de la Peza, Francisco G. de Arce, Alberto Garza, Darío Ibargüengoitia, Claudio y Eduardo Limón, Manuel Marroquín y Rivera, Carlos A. Salas López y José Leopoldo Villela (González, 1921-1922:1). Los abogados De la Mora, De la Peza, De Arce Marroquín y Rivera, Salas López y los hermanos Villela también eran miembros de los Caballeros de Colón. Salas, De la Peza, De la Mora y ViIlela del Partido Católico Nacional. Esto muestra cómo el grupo de católicos fundadores de esta agrupación lo fueron también de otras, incluyendo también a sus esposas, que sin duda pertenecían a la Unión de Damas Católicas (1912). Sin embargo, a esta organización podía pertenecer cualquier padre o madre de familia que comulgara con sus ideales.

${ }^{3}$ Estatutos generales de la Unión Nacional de Padres de Familia, México, abril de 1917.
} 
La frase que se convirtió en su leitmotiv era que sólo a los padres de familia corresponde el derecho de educar a sus hijos, pues alegaban que, una vez en manos de la escuela oficial, la familia dejaba de influir en el desarrollo moral del niño. Los miembros de la UNPF veían en el laicismo la mayor amenaza que se cernía sobre la formación intelectual y moral de los niños, por no tratarse de un laicismo "neutro", sino infundido de un espíritu combativo y antirreligioso. Temían que, al faltarles los valores cristianos y recibir otro tipo de adoctrinamiento, sus mentes se convertirían en presa fácil de ideas ajenas a las tradiciones de la moral cristiana. El derecho de los padres para educar a los hijos se incorporó al concepto de libertad de enseñanza, y juntos se manejaron a través de los años como el principal argumento para derogar el artículo $3^{\circ}$ constitucional.

Los integrantes de la UNPF también pretendían erigirse en vigilantes de que no se difundieran doctrinas falsas que atacaran a la "única verdad, la Católica, Apostólica, Romana", a través de los informes que recibían de sus hijos (González, 1921-1922: 8).

Como en la mayoría de las organizaciones católicas, su estructura fue piramidal: su centro estaría en la capital, desde donde se dirigirían y orientarían a los centros estatales y municipales. Asociaciones afiliadas a la UNPF se establecieron en varias partes del país, desde donde hicieron un llamado especial a los padres de familia para que se sumaran a la organización y "lucharan por la restauración social de la familia y, de esta manera, por la salvación de la patria" (UNPF, circular s.p.i.).

El único medio con que contaban los católicos para mantener un lugar dentro de la educación nacional y para luchar contra el laicismo oficial eran las escuelas particulares, donde podían continuar con un proselitismo constante en materia religiosa; por ello no cedieron en sus demandas, aun a pesar de los constantes embates que recibieron. Cabe destacar, como lo hace Cesáreo L. González (1921-1922: 109-119), miembro fundador, que para el sostenimiento y creación de escuelas particulares (confesionales) los centros municipales de la UNPF contaron con cooperativas de producción y consumo, que a su vez promovían el mutualismo. Junto a esto, se podían crear empresas aseguradoras con las aportaciones de los socios; en estas iniciativas se trasluce el impacto del catolicismo social.

En noviembre de 1918, el Episcopado mexicano elaboró un documento conocido como "El acta de Chicago", en la que se invitaba a los católicos a realizar acciones de índole política; se les daban instrucciones "para dirigir en forma segura la acción del clero y del pueblo católico de México", con el fin de establecer una paz religiosa en la república. Nuevamente, se pedía la libertad de enseñanza en todos los niveles de educación y la no participación del Estado en la enseñanza particular (Loaeza, 1980: 35). Estas peticiones, aunadas a las de la UNPF y a las de otros grupos de derecha, presionaron al presidente Carranza para que apoyara un proyecto de reforma de ley al artículo $3^{\circ}$ en 1918, cuyo texto decía: "La enseñanza es libre: pero será laica la que se dé en los establecimientos oficiales de educación, lo mismo 
que la enseñanza primaria, elemental y superior, que se imparta en establecimientos particulares" (Meneses, 1986: 179).

Carranza justificaba esta iniciativa, ante la falta de libertades que representaba el artículo aprobado, pues aceptaba que era francamente prohibitivo y restrictivo de la libertad. Este proyecto equivalía a seguir permitiendo la enseñanza religiosa, sin necesidad de eliminar la laicidad del artículo constitucional. Uno de los objetivos que se planteó Carranza al promover dicha reforma era evitar el enfrentamiento entre el poder civil y el clero, tal y como sucedería años más tarde. Aunque la iniciativa no prosperó, el hecho de que el mismo Carranza hiciera la propuesta que serviría de bandera para que la Unión y otros organismos conservadores y religiosos repitieran durante años la misma demanda, sustentándola en la "legitimidad revolucionaria".

El artículo $3^{\circ}$ no se aplicó a la letra, ya que hubo tolerancia hacia las escuelas confesionales, tanto en el gobierno de Carranza como en el de Adolfo de la Huerta, incluso en el de Álvaro Obregón. No obstante, el contenido del artículo era una piedra en los zapatos de los católicos, pues sabían que, existiendo el ordenamiento en la Constitución, en cualquier momento podía ponerse en práctica. Por ello continuaron las protestas y las organizaciones reivindicadoras de la "libertad de enseñanza" fueron haciéndose cada día más fuertes. Una de las más constantes fue la Liga de Estudiantes Católicos (1911), que posteriormente sería parte de la Asociación Católica de la Juventud Mexicana (ACJM). Esta organización surgió como reacción al "estado de relajamiento social resultante de la exclusión de Dios de las leyes" que había propiciado el positivismo; el fin de la asociación "no es otro que la coordinación de las fuerzas vivas de la juventud católica mexicana para restaurar el orden social cristiano en México" (Rius, 1963: 43).

En 1919, la ACıM asumió la tarea de organizar a todos los habitantes del país [sic] "para que protestaran hasta alcanzar la derogación de los artículos $3^{\circ}[y] 130^{\circ}$ de la Constitución". Esta organización llegó incluso a proponer en 1920, en el Congreso Regional de Jalisco, la desobediencia civil. Recordaba a los padres de familia "la inconveniencia y la ilicitud que le[s] obliga en conciencia a no enviar a sus hijos a esas escuelas [las oficiales]" (Rius, 1963: 141), a la vez que señalaba la necesidad de establecer escuelas católicas, fueren o no patrocinadas y sostenidas por los grupos "acejotaemeros".

Durante el gobierno de Obregón, la oposición al artículo $3^{\circ}$ fue poca. Con José Vasconcelos se abrió la nueva Secretaría de Educación Pública, y tanto el presidente como el secretario quisieron dar un impulso a la demanda educativa. Vasconcelos llegó incluso a denostar el laicismo: "la misma experiencia rusa nos está mostrando que no se sofoca el sentimiento religioso con prohibiciones, pues únicamente se le bastardea [...]. El laicismo debe querer decir únicamente tolerancia de los alumnos de religión diferente en países poblados por distintas razas" (Vasconcelos, 1972: 119). Obregón, a pesar de ser más radical, no deseaba 
crear un conflicto directo con la Iglesia, por lo que no ejerció ninguna presión efectiva para que la Constitución fuera obedecida.

Sin embargo, la postura pasiva del Estado no solventó las ambiciones de la Iglesia, que no se resignaba a ver limitada su influencia en el campo educativo; su posición se hizo más beligerante día con día. La Iglesia sumó sus fuerzas y fortaleció sus agrupaciones. Entre las más interesadas en obtener reivindicaciones educativas destaca la Unión Popular de Jalisco (1924), cuyos militantes hablaban de la escuela oficial como "escuela del miedo", puesto que "obligaba al niño a esconderse para realizar sus prácticas religiosas". ${ }^{4}$

En 1926, el padre Bernardo Bergoend, fundador de la ACJM, propuso la creación de la Liga Defensora de la Libertad Religiosa, grupo que incorporó en sus filas a un gran número de organizaciones católicas durante la guerra cristera. Esta organización defendería "los derechos reconocidos universalmente a la Iglesia y la libertad de enseñanza negada en el artículo $3^{\circ}$ constitucional". Obviamente, la UNPF se sumó a estas organizaciones, que debatieron el monopolio estatal de la educación, y señalaron a la escuela oficial como perjudicial para la paz y la familia (Conzález, 1921-1922: 116). Asimismo, consideraban que en las escuelas laicas se pervertía la inteligencia y se producían hombres dañinos para la sociedad y su gobierno. A los que atacaban la religión en las escuelas se les debía considerar, según decía un miembro de la Asociación Católica Nacional, "enemigos públicos y jurados del orden y de la paz de la familia, de la sociedad y de todo gobierno honrado", implicando con su aseveración la imposibilidad de formar conciencias honestas con una educación de tipo oficial (Conzález, 1921-1922: 109).

La mayoría de estas organizaciones tenía entre sus consideraciones la defensa de la educación católica. En 1923, los Caballeros de Colón crearon la Cruzada Nacional en Defensa del Catolicismo, que entre sus objetivos tenía la enseñanza de la doctrina católica, la creación y fomento de escuelas confesionales, para "combatir la corrupción de las costumbres, la escuela antirreligiosa y el sindicato socialista"5 (Pérez, 2010: 114).

En el periodo de persecución religiosa que se extiende de 1926 a 1938, se vivió con un espíritu combativo en que la Iglesia, apoyada por la UNPF, decidió en 1926 crear el Secretariado Arquidiocesano de Educación, cuyo objetivo era "la coordinación de las escuelas, la promoción de su calidad pedagógica, su defensa ante las autoridades civiles" y cuya "finalidad específica era la inspiración cristiana en la formación integral del hombre, tanto en el ambiente escolar como fuera de él" (Cervantes, 1976: 11 y 14). Desde entonces, y hasta bien entrada la década de los treinta, se exhortaba a los padres de familia a no enviar a sus hijos

\footnotetext{
${ }^{4}$ Uno de ellos fue Anacleto González Flores, un militante cristero que estaría a favor de la resistencia pasiva mediante el boicot y la omisión del pago de impuestos.

${ }^{5}$ Circular del diputado de estado de los Caballeros de Colón, Luis G. Bustos, México, 6 de noviembre de 1923.
} 
a escuelas laicas, amenazándoles de pecar gravemente (Pérez, 2010: 59). ${ }^{6}$ En estos años se cierran escuelas confesionales, se suspende el culto en las iglesias y las organizaciones religiosas actúan en la clandestinidad.

Hacia 1932 era tal la agitación provocada por los católicos ante las leyes persecutorias, que el papa envió un mensaje al obispo Leopoldo Ruiz y Flores prohibiéndole discutir el tema. No obstante, las autoridades eclesiásticas exhortaron a las familias católicas a que no enviaran a sus hijos a las escuelas laicas. Las relaciones entre la Iglesia y las autoridades educativas llegaron a un estado crítico, que se agravó cuando la SEP lanzó el proyecto para hacer obligatorio un curso de educación sexual. La UNPF se declaró en contra de ésta por considerarla "innecesaria y peligrosa"; sostuvo que, en manos de maestros no capacitados, era sumamente riesgosa, ya que podrían contar con los "medios para violar niños inocentes"; calificaron al proyecto como "un complot comunista para destruir la estabilidad social de México", al debilitar a la familia como núcleo central de la sociedad (Britton, 1976: 100-101). Luis Bustos, su presidente, propuso que se organizara una huelga y anunció un boicot económico y social contra cualquier maestro que impartiera esa materia. El movimiento tuvo alguna fuerza en el Distrito Federal, donde no más de 49 escuelas de las 485 existentes se vieron afectadas (Excélsior, 7 de mayo de 1934).

Por otro lado, la acción del ala izquierda del Congreso apoyó en 1934 la reforma socialista del artículo $3^{\circ}$. El arzobispo se declaró abiertamente contra esta reforma e instó a los católicos a dejar de concurrir a las escuelas donde se impartiera la educación socialista.

La UNPF veía en la educación sexual y en la educación socialista dos amenazas a la libertad; consideraron que el socialismo educativo era una consecuencia de la educación sexual y una argucia del gobierno para destruir a la familia y la moral de la sociedad. Este organismo inició una campaña en contra del gobierno, a través de mítines y de la prensa mediante la publicación de libros y folletos (La Prensa, 29 de septiembre de 1934).

Las protestas más fuertes de la UNPF se hicieron sentir hacia 1939, en vísperas de la elaboración de la Ley reglamentaria del artículo $3^{\circ}$. La UNPF decía ver en la educación socialista una amenaza del comunismo internacional: "ila amenaza de convertirnos en una dependencia rusa!”, aunque lo que más le preocupaba era la limitación que se imponía a la enseñanza religiosa (Meneses, 1988: 351).

\footnotetext{
6 "Instrucción pastoral que dirigen a su venerable clero los Ilmos. y Rvmos. prelados de la Provincia eclesiástica de México", México, 25 de mayo de 1924.
} 


\section{El modus vivendi y la oportunidad de crecer}

Entre 1939 y 1950, la "unidad nacional" que propuso el avilacamachismo buscó limar las asperezas y debates que propició el socialismo educativo. Sin embargo, el conflicto del Estado con la Iglesia sólo experimentó "un acomodo circunstancial, pragmático y hasta duradero", como bien señala Roberto Blancarte (2011: 24), quien considera que la jerarquía se acomodó con el gobierno, a pesar de que no compartía ninguno de sus postulados básicos y más bien estaba en contra de ellos. La estrategia seguida por la Iglesia y sus organizaciones de masas, que muy bien ejemplifica la UNPF, evitó el confrontamiento directo empleado años atrás y adoptó una oposición pacífica, pero firme, sobre todo en los principios relacionados con el magisterio eclesial (Blancarte, 2011: 24). A partir de entonces, se diría que "hay, por lo menos [...] una contienda permanente, una lucha sorda dirigida por la jerarquía eclesial, integral-intransigente (o neointransigente), destinada a la recuperación y la diseminación del proyecto social católico" (Blancarte, 2011:24).

La reacción de la UNPF fue muy favorable a este acomodo, sin embargo, su posición combativa siguió siendo la misma: querían la libertad de enseñanza para recuperar prerrogativas perdidas y para ampliar su campo de acción. En 1940, decidió levantar un "censo plebiscito" para pedir a Ávila Camacho que modificara el artículo 30; promovió entre la feligresía que se enviaran mensajes al presidente, al secretario de Educación y las cámaras, con el siguiente texto: "Aprobamos la labor de la Secretaría de Educción que está resolviendo en forma patriótica y enérgica la cuestión educacional. Estamos dispuestos a cooperar para que se reforme el Art. $3^{\circ}$ constitucional de manera que consagre y garantice la libertad de enseñanza" (UNPF, 22 de noviembre de 1941, circular núm. 14). A la vez pedía que enviaran su adhesión a los diarios y organizaran reuniones escolares. También mostró su satisfacción por la renuncia del secretario de Educación, Luis Sánchez Pontón, "reconocido comunista", sobre todo porque el nuevo secretario, Octavio Véjar Vázquez, tenía una visión más acorde a sus ideas. Esto dio lugar a "una sensación agradable de alivio", y se pensó en que el régimen avilacamachista concedería la libertad de enseñanza, "cediendo al clamor del pueblo" (UNPF, 18 de noviembre de 1941, circular núm. 13).

En otro gesto de acercamiento, la Secretaría de Educación Pública (SEP) invitó a los representantes de la UNPF para que formularan un nuevo proyecto de ley reglamentaria. La UNPF se sintió fuerte y decidió organizar una gran campaña para derogar el artículo socialista. Esta acción no fue del todo infructuosa, ya que el presidente Ávila Camacho decidió reglamentar el artículo $3^{\circ}$. Dicha ley aludió a los llamados de los padres de familia para "no divorciar a la escuela de la familia" y reconoció en ellos su misión educadora y, aunque mantenía el término "socialista", era moderada y fue el antecedente inmediato del artículo $3^{\circ}$ renovado de 1946. 
Sin embargo, la UNPF no deseaba tolerancia, sino aceptación legal de la enseñanza religiosa. En diciembre de 1945, el presidente Ávila Camacho envió al Congreso un proyecto de ley para la reformar el artículo $3^{\circ}$, eliminando su definición de socialista, que coincidió con otro, enviado por la UNPF, el cual agregaba un párrafo inicial que decía: "El Estado reconoce y garantiza la libertad de enseñanza" (UNPF, 13 de diciembre de 1945, circular núm. 43), que no fue incluido en la redacción final. Sin embargo, la jerarquía católica vio en la reforma un avance hacia sus pretensiones de libertad religiosa.

La supuesta infiltración comunista, que se avizoraba como consecuencia de la segunda guerra mundial, fue otra de las preocupaciones de la Iglesia y de la UNPF. Por medio de informantes anónimos llegaban a la organización noticias como ésta: "Nos informan que en la Secretaría de Educación, los comunistas se están apoderando de muchos de los llamados puestos clave para intensificar el comunismo [...], pues es sabido que con los dineros del pueblo se sostienen profesores antipatriotas que más bien tratan de servir a Moscú" (UNPF, 2 de febrero de 1947, circular núm. 49).

Su reacción fue enviar cartas a Jaime Torres Bodet, secretario de Educación, y al presidente Miguel Alemán, previniéndoles de esta "amenaza comunista". Esa labor se extendió hasta la Normal, donde la UNPF hizo un Ilamado a los padres de familia, "para que interpongan toda su autoridad, a fin de impedir que la Normal siga convirtiéndose en centro de inmoralidad, de agitaciones que lesionan gravemente no sólo la integridad de la familia, sino también el orden social y son un grave mal para México" (UNPF, 2 de febrero de 1947, circular núm. 49).

En 1949, la SEP publicó el Reglamento para las Asociaciones de Padres de Familia, lo que aprovechó la UNPF para organizarse en todas las escuelas particulares, pues las escuelas que pertenecían a la Unión estaban exentas de formar parte de los organismos oficiales. Las relaciones entre la UNPF y la SEP entraron en "un buen momento", situación que la primera aprovechó para reanudar un plebiscito que lanzó en 1941 para reformar el artículo $3^{\circ}$. Posteriormente, publicó una carta abierta en varios periódicos, en la que pedía la libertad de enseñanza en cumplimiento de la "Declaración Universal de los Derechos del Hombre", que reclamaba "la libertad de pensamiento, de conciencia y de religión manifestado y ejercido por la enseñanza", así como el derecho de los padres de familia a "escoger el tipo de educación que ha de darse a sus hijos" (UNPF, 13 de diciembre de 1950, circular núm. 71).

Esa "paz" complaciente tuvo sus límites en 1958 con el Plan de Once Años,? Adolfo López Mateos propuso la publicación de libros de texto gratuito para todos los niños de primaria, con el fin de que la educación fuera efectivamente democrática. El texto se convirtió en único y obligatorio, y la discusión que esto provocó alcanzó niveles alarmantes, sobre

\footnotetext{
7 "Plan Nacional para la Expansión y el Mejoramiento de la Educación Primaria", coloquialmente conocido como Plan de Once Años.
} 
todo en las escuelas confesionales. La UNPF encabezó la oposición a la iniciativa, cuya reacción más violenta se llevó a cabo en la ciudad de Monterrey, donde se realizó una gran manifestación al grito de ¡Cristianismo, sí!, ¡comunismo, no!, al que se unieron otros grupos como el Movimiento Familiar Cristiano, el Partido Acción Nacional, miembros de la banca, la industria y el comercio y, obviamente, la Iglesia. El movimiento se extendió a otras ciudades, como León, Guanajuato, Zamora, Michoacán, Chihuahua y el Distrito Federal. El debate fue acalorado, pero ante la resistencia de la autoridad a estos reclamos, poco a poco los ánimos se calmaron cuando las escuelas particulares tuvieron la seguridad de que los textos no eran "tan obligatorios" ni únicos, y que podían utilizar otros textos autorizados.

Los cambios que se dieron en la Iglesia después del Concilio Vaticano II tuvieron importantes repercusiones en el campo de la educación católica, al abrirse a posiciones "más democráticas". En efecto, algunos sectores de la Iglesia, como los jesuitas y maristas, siguieron considerando prioritaria a la escuela, pero no como había funcionado hasta entonces. Se manifestó la necesidad de una "renovación total y profunda" para dejar de "perpetuar y consolidar estructuras injustas". Se pretendía, por el contrario, que la educación católica fuera uno de los mejores medios para transformarlas. Esto llevó a un cuestionamiento interno muy serio de la Iglesia sobre la función de las escuelas confesionales, y del papel que éstas cumplían como reproductoras de un sistema social injusto.

Los años que van desde la aparición de los libros de texto gratuito en 1959, hasta su reforma en 1973, coinciden con el periodo conocido como del "desarrollo estabilizador". El presidente Gustavo Díaz Ordaz ejerció la represión institucionalizada, que desembocó en el movimiento estudiantil de 1968.

La reforma educativa fue una de las demandas que puso en práctica Luis Echeverría. En 1973, expidió la Ley Federal de Educación. Para este momento ya no hubo impugnaciones de la Iglesia, sino más bien ésta alababa los esfuerzos de las autoridades educativas de los últimos años. Aunque la Iglesia siguió considerando como prioritaria a la escuela, manifestó la necesidad de una "renovación total y profunda" que hiciera posible una sociedad menos desigual. Sin embargo, ya en estos años encontramos un desfase de puntos de vista entre una Iglesia más progresista y la UNPF, que no modificó su postura tradicional.

Como resultado de la reforma educativa, en 1972 vieron la luz nuevas versiones del libro de texto gratuito. Esta vez, el debate se suscitó no por su existencia, sino por el contenido de algunos volúmenes de ciencias sociales y ciencias naturales. La UNPF encabezó los reclamos: rechazó el texto de ciencias sociales "por contener una ideología tendenciosa, socializante y medio sutil del gobierno para transformar su estructura liberal en un claro socialismo de Estado, tendiente a desembocar en un comunismo ateo"; también defendió que los padres de familia conservaran el derecho a ser ellos y no la escuela quienes dieran educación sexual (Excélsior, 3 de febrero de 1975). Repartió volantes que decían: "Los libros de texto contienen 
ideologías inaceptables para la fe cristiana y para la moral humana", lo cual desconcertó a los fieles que enviaban a sus hijos a las escuelas públicas (Excélsior, 21 de febrero de 1975).

El Episcopado tomó una postura más conciliadora y consideró que los textos "eran perfectibles", pero que podían ser utilizados en las escuelas. A raíz del debate que esto provocó, la UNPF se alineó con la extrema derecha y a sus filas ingresaron miembros de Movimiento Universitario de Renovadora Orientación (MURO), lo que creó una división interna muy severa y provocó que la Iglesia católica se deslindara en ese momento de la organización.

\section{La reforma al artículo $3^{\circ}$ en 1992 , ¿un triunfo para la UNPF?}

La tan ansiada reforma al artículo $3^{\circ}$ por la que luchó la UNPF a todo lo largo del siglo XX, se empezó a perfilar como una realidad hacia 1992, cuando el presidente Carlos Salinas de Gortari planteó la necesidad de una nueva relación entre Iglesia y Estado, basada en el reconocimiento jurídico de las iglesias, que si bien en su planteamiento inicial dejaba fuera la cuestión educativa, finalmente fue parte de las reformas realizadas a la Constitución entre 1992-1993. ${ }^{8}$

En la discusión de las reformas "con olor a anticlericalismo" (Olimón, 2011: 3), el asunto de la laicidad seguía estando vivo, pues los legisladores tenían aún recelo y temor de que este concepto se modificara en el artículo $3^{\circ}$, no obstante, algunos diputados moderados señalaron a la laicidad como "condición necesaria para que quienes profesen cualquier religión, o quienes no tengan ninguna, cuenten con un ámbito de libertad" (Olimón, 2011: 9). Manuel Olimón sostenía que, por el número masivo de católicos en el país, el Estado debía guardar hacia ellos consideraciones diferenciadas (Olimón, 2011: 27). En la exposición de motivos de la reforma se afirma:

\footnotetext{
El laicismo no es sinónimo de intolerancia o de anticlericalismo, ni censura [de] las creencias de una sociedad comprometida con la libertad. Lo que se busca es evitar que la educación oficial privilegie alguna religión o promueva el profesar una religión, pues ello entrañaría lesionar la libertad de religión de quienes optan por mantenerse al margen de los credos (Sánchez, 1992: 18).
}

Los católicos sustentaban sus reclamos a la reforma en la aprobación de la "Declaración Universal de Derechos Humanos" (1948) y en el Pacto Internacional firmado por México en

\footnotetext{
${ }^{8}$ Salinas hizo público el proyecto que se aprobó el 28 de enero. "México, las reformas constitucionales de 1992", Boletín mexicano de derecho comparado, núm, 151, UNAM, 2018.
} 
1981. Sánchez Medal, quien fuera presidente de la UNPF, abundó en esta postura al señalar que la Declaración señalaba que: "Los padres tendrán derecho preferente a escoger el tipo de educación que habrá de darse a sus hijos" y el Pacto Internacional que "Los Estados [...] se comprometen a respetar la libertad de los padres y, en su caso, de los tutores legales, para garantizar que los hijos reciban la educación religiosa y moral que esté de acuerdo con sus propias convicciones" (Sanchez, 1992: 8).

Finalmente, en palabras de Jorge Adame Goddard, "las reformas constitucionales significaron un progreso en cuanto al reconocimiento y protección de esta libertad [manifestar la religión o creencias que] se considera el fundamento de todas las demás libertades o derechos de la persona frente al Estado y la sociedad", y que en el caso de la educación estas reformas "son las más importantes" (Adame, 1992: 13). Considera, sin embargo, que este avance no estaba a la altura de la doctrina internacional de los derechos humanos, la cual señalaba que "los padres tienen derecho de que sus hijos reciban la educación religiosa y moral que esté de acuerdo con sus propias convicciones, porque, en la práctica, tal derecho lo podrán hacer efectivo en México sólo los padres que pueden pagar una colegiatura en una escuela privada". La educación religiosa era, pues, un privilegio, en tanto que deja sólo dos posibilidades: la primera, consistente en multiplicar las escuelas privadas gratuitas promovidas por las iglesias, y la segunda era que se impartiera religión en las escuelas públicas pagadas por las asociaciones religiosas (Adame, 1992: 13-14).

A pesar de las críticas a la reforma del artículo $3^{\circ}$, la libertad de enseñanza religiosa avanzó significativamente. La UNPF consideró esta reforma como un triunfo propio ( La Jornada, 2 de septiembre de 2003). El artículo $3^{\circ}$ permitió que en las escuelas privadas se impartiera educación religiosa, con lo que la UNPF lograba su objetivo de lucha a todo lo largo del siglo XX.

\section{Una Unión en unión con otros}

Al inicio del siglo XXI, la UNPF ya era entonces un organismo fuerte, reconocido y establecido en muchos estados del país. El triunfo del Partido Acción Nacional en las elecciones del año 2000 favoreció su supervivencia, así como la de otros grupos similares que se fueron construyendo al amparo de la Iglesia, y de un gobierno menos jacobino y anticlerical, como aquél de 1917: ${ }^{9}$ su permanencia se justificaría debatiendo asuntos educativos de toda índole.

\footnotetext{
${ }^{9}$ A principios del siglo XXI, contaba con treinta y ocho comités estatales, seis regionales y cuatro en la Ciudad de México, lo que supone una cobertura a nivel nacional. Sus miembros sumaban 1,100,000 afiliados (Reforma, 10 de diciembre de 2003).
} 
El vertiginoso cambio de la sociedad relacionado con el comportamiento sexual, la secularización de las costumbres y la apertura de sectores de la Iglesia católica hacia posturas más democráticas, dieron la pauta para que la UNPF reavivara otras demandas, como su oposición a la educación sexual, que se basaba en la promoción de la anticoncepción con la práctica del sexo seguro y el uso del condón, con carteles que contenían frases como ésta: “¿Dónde estarías tú si tu padre hubiese usado condón? (La Jornada, 10 de diciembre de 1989). La nueva estrategia se centraba ahora en la moralización del ambiente, en el combate contra la pornografía en los medios y la lucha por la "integridad familiar". También se abrió a los medios con objeto de mejorar su imagen. Inició una labor editorial con publicaciones como la revista Cumbre, ${ }^{10}$ con una intención informativa y formativa para sus agremiados; produjo también audios y videocasetes con el mismo fin.

La UNPF defendió al secretario del Trabajo, Carlos Abascal, quien detonó un escándalo al oponerse a que su hija leyera la novela Aura de Carlos Fuentes, recomendada por la profesora de literatura Georgina Rábago, al que calificó como "uno de los autores que la mercadotecnia ha encumbrado" (Adame, 2007). También se manifestó a favor de las autoridades panistas de Baja California, quienes impidieron el aborto que solicitaba la joven Paulina Ayala López, víctima de violación (Siete Días, 13 de mayo de 2001). Otros temas abordados fueron la drogadicción y la violencia en las escuelas, mediante la inculcación de valores cívicos e impedir que se difundieran series televisivas plagadas de violencia (Excélsior, 3 de febrero de 2003).

Un gran tema se inició en enero de 2003 en el Primer Encuentro Nacional de Padres de Familia y Maestros, en el Auditorio Nacional, ${ }^{11}$ con el objetivo de elevar la calidad y alcanzar la equidad en la enseñanza, para desterrar "la distinción entre mexicanos de primera y de segunda que hoy nos agravia" (Excélsior, 2 de febrero de 2003.). Esta reunión fue muy comentada en la prensa, sobre todo en La Jornada, que mostró un sarcasmo recurrente al referirse al sector femenino participante con notas como ésta: "madres chic de fina estampa, de legionarias-millonarias de Cristo, lucían refulgentes crucifijos de fina pedrería y oro ante los ojos azorados de decenas de sencillas maestras" o "docenas de maestros y maestras se asomaban al Primer Mundo", entre otros comentarios sarcásticos. La gran protagonista del evento fue la esposa del entonces presidente Vicente Fox, Martha Sahagún, quien, junto con la profesora Elba Ester Gordillo, secretaria general del Sindicato Nacional de Trabajadores de la Educación (SNTE), proclamó "el inicio de una nueva etapa en la historia de la educación mexicana, a partir de la alianza entre maestros y padres de familia"; la Alianza se manifestó

\footnotetext{
${ }^{10}$ La UNPF edita la revista Cumbre, de editorial Forja, apoyada publicitariamente por empresas como Cerillera La Central, Seguros Tepeyac, Afianzadora Insurgentes, Alfombras Luxor y Mohawk y Colchones Simmons (Villamil, 1989).

${ }^{11}$ Ante la presencia de casi diez mil personas, con la realización de 1,250 eventos municipales, 45 regionales y 16 delegacionales, en los que se concentraron las sugerencias de 230,276 padres de familia y maestros.
} 
a través de la vinculación del SNTE con la Fundación Vamos México y la UNPF (La Jornada, 3 de febrero de 2003). En el encuentro, Sahagún retomó el discurso tradicional de la derecha y de la UNPF, y señaló que los padres de familia "somos y debemos ser protagonistas del proceso educativo. El hogar es el centro de aprendizaje y la familia es corresponsable de las actividades académicas de nuestras escuelas" (La Jornada, 3 de febrero de 2003). Según ella, esta alianza modificaba relaciones anteriores, dando a México "el impulso de país humanista, socialmente responsable y auténticamente democrático", que abría la puerta para la conciliación (La Jornada, 3 de febrero de 2003).

El acuerdo consistía en el compromiso para trabajar juntos; el sindicato magisterial con la parte editorial y de capacitación y asesoría, así como de la promoción de "valores" ( $L a$ Jornada, 3 de febrero de 2003). El sindicato editaría 36 millones de ejemplares del texto de la fundación, titulado Guía de padres, serie de tres libros con consejos a los progenitores, que se presentó como "una alianza generosa por encima de las ideologías, credos religiosos y partidos políticos, justamente porque se trata de la educación, entendida como construcción del espacio compartido y la cultura común de los ciudadanos" (La Jornada, 3 de febrero de 2003).

El dirigente sindical Rafael Ochoa señaló que, a partir de la alianza, la escuela se convertía en "centro motor de la organización social", al considerar a los padres en el diseño de la política educativa. Tal como habían solicitado grupos ligados a la Iglesia católica, como la UNPF, Ochoa anunció que se restablecía el diálogo entre padres y maestros para "dejar atrás las desconfianzas" que se generaron a lo largo del tiempo (La Jornada, 3 de febrero de 2003), y atribuía el mérito del avance a Elba Esther Gordillo. Como en los mejores tiempos de la UNPF, Ochoa manifestó que "es en la casa donde el alumno recibe la más importante influencia que habrá de normar su comportamiento" (La Jornada, 3 de febrero de 2003).

La Guía competía, a su vez, con un libro que con esa misma intención había publicado anteriormente la SEP, titulado Los libros de mamá y papá, que la UNPF rechazó por considerar que promovían "el libertinaje sexual" (La Jornada, 23 de febrero de 2003). Recibió también críticas de otras organizaciones de derecha, como de Jorge Serrano Limón, dirigente del Comité Nacional Provida, quien señalaba que al texto le faltaban muchos aspectos y fundamentalmente "resaltar ciertos valores familiares" (El Norte, 28 de febrero de 2003). Por otra parte, la prensa de izquierda no dejó de externar su postura contra esta alianza, en la que hacía patente el cambio de las organizaciones a las que ahora se veía "del brazo y por la calle" (La Jornada, I de febrero de 2003).

Dos días después de la reunión, el presidente de la UNPF decidió pedir a la SEP que retirara los libros de texto para secundaria, por considerar que contenían "una información distorsionada de nuestra historia". La acusación consistía en que en dichos materiales se culpaba al ejército del movimiento estudiantil de 1968. Con la autoridad otorgada por su alianza con Vamos México y el SNTE, pidió a las autoridades educativas que fueran más 
cuidadosas con la información de los textos y tuvieran en cuenta que "el estudio de la historia debe consignar hechos, pero sin tendencias ideológicas, partidistas y doctrinarias", y solicitó a Reyes Tamez Guerra, secretario de Educación Pública, y a Lorenzo Gómez Morín, subsecretario de esa dependencia, a evitar el tener que embodegar los libros de texto, como sucedió cuando Ernesto Zedillo fue secretario de Educación (El Informador, 5 de febrero de 2003).

La SEP se comprometió a realizar una revisión de los planes y programas de estudio de la escuela secundaria. Subrayó que las autoridades de esa secretaría y los representantes de la Cámara Nacional de la Industria Editorial Mexicana se reunirían para garantizar a la sociedad que los contenidos de los libros no obedecerían a intereses personales o sectarios, y que se respetarían los hechos históricos con base en la documentación histórica (Excélsior, 5 de febrero de 2003).

Otro tema vinculado al anterior fue el de la elaboración de textos para una nueva asignatura que sustituiría a la de civismo, llamada formación cívica y ética, desde la cual se pretendía fortalecer la "educación en valores" en la primaria. Para ello se abriría un concurso para la elaboración del libro de texto, con el objeto de que las editoriales presentaran distintos títulos para ser puestos a consideración de las escuelas. La SEP pidió a la UNPF convocar al concurso, dándole así un reconocimiento tácito (La Jornada, 27 de abril de 2003).

También pidió a los maestros "paristas" a que renunciaran a sus plazas. Guillermo Bustamante Manilla, su presidente, elaboró una propuesta que contemplaba la colaboración de especialistas, como psiquiatras y paidopsiquiatras, para valorar a los trabajadores de la educación en activo y a los de nuevo ingreso al servicio magisterial, con la finalidad de detectar posibles desviaciones mentales en los docentes (La Jornada de Morelos, 13 de octubre de 2003).

La misión de la UNPF continuó con su objetivo ampliado: el reclamo de enseñar religión en las escuelas no sólo particulares, sino también en las públicas. En agosto de 2003, su dirigente pidió que "se reconozca el derecho de los padres de familia a educar a sus hijos, de acuerdo con sus principios y convicciones. Para su presidente, la educación no debía ser laica, obligatoria y gratuita, sino libre, obligatoria y gratuita", y sustentaba su reclamo en que el 90 por ciento de los mexicanos eran católicos (La Jornada, 28 de agosto de 2003). La posibilidad de una petición como ésta sólo se puede entender en el marco de un México en transición de un liberalismo anticlerical, que perdió su vigencia ante el retorno de posturas muy conservadoras, no sólo dadas por la ideología del entonces presidente Vicente Fox y su esposa, sino también por algunos sectores del mismo magisterio representados en el SNTE, la CNTE y, por supuesto, de la Iglesia, sin cuyo apoyo no se entendería su acción política.

El rechazo homofóbico y contra la educación sexual, demanda histórica de la UNPF, 12 fue evidente desde 2005, cuando Bustamante manifestó que enviaría una carta al secretario de

12 La UNPF siguió en este punto la misma postura de la Iglesia católica, que en ambas instituciones se ha mantenido hasta la fecha. 
Salud, doctor Julio Frenk, para solicitar que se retiraran de los medios los anuncios en favor de una campaña que "promueve el homosexualismo" y tenía su origen en el "machismo". La carta no fue contestada, pero la UNPF insistió en el tema, solicitando que se suspendiera la cápsula llamada "La cena" y cualquier otra. Solicitó al secretario Frenk "atender", es decir, buscar para los homosexuales, la cura de su "desviación sexual".

\section{A cien años del inicio}

Bernardo Barranco considera que "la laicidad del Estado es un instrumento fundamentalmente jurídico, no una ideología o un planteamiento histórico, que dota al Estado de diferentes elementos: una clara separación entre la Iglesia y el Estado, la garantía de libertad religiosa del Estado laico, la equidad en las creencias y que el Estado está obligado a proteger las minorías" (Barranco, 2016). La laicidad, vista como instrumento jurídico, implica una mayor democracia que evita los partidismos hacia alguna religión específica (Inqro, 2016).

Si la laicidad, que había sido el motivo principal de la existencia de la UNPF, dejó de tener esa connotación ideológica - al menos para una mayoría liberal- y el artículo $3^{\circ}$ había sido modificado, el motivo fundamental de la existencia de la UNPF perdía su sentido.

La justificación actual para su permanencia tiene que ver con la misma bandera que han tomado otras instituciones de derecha, sobre todo las más radicales. El punto del debate se centra ahora en la campaña contra los matrimonios igualitarios. Esta organización se vinculó al Frente Nacional por la Familia (un grupo de organizaciones de derecha), que buscaba que el paquete de iniciativas promovido por Enrique Peña Nieto en mayo de 2016 no se aprobara.

El Frente, según la vocera del movimiento y presidenta de la UNPF, Consuelo Mendoza, está constituido por "millones de padres de familia y más de mil instituciones de la sociedad civil organizada de todo el país", cuyo objetivo fundamental es defender lo que llaman "matrimonio natural", conformado entre un hombre y una mujer. El Frente demanda el cambio del artículo $4^{\circ}$ constitucional "para que esté protegida la familia, [y] para proteger el matrimonio natural" (Rocha, 2016). Para apoyar esta solicitud, la UNPF lleva a cabo campañas de sensibilización "sobre las bases del matrimonio y la familia", así como acciones que robustezcan "los valores tradicionales que han demostrado ser infalibles, como la base del progreso y la fortaleza de la familia", los cuales son incompatibles con "cualquier otra forma o principio de unión conyugal/familiar [que,] fuera de dicho contexto, representan un riesgo y una amenaza para el futuro social de las próximas generaciones" (Ulloa, 2015).

En relación con la educación, sostiene que está en contra de lo que se enseña a los niños en los nuevos programas educativos, por ejemplo, que sean adoptados y vivan con homosexuales; que puedan cambiar de sexo sin la intervención de padres de familia o tutores; que 
a través de los libros de texto de la SEP y desde preescolar, les enseñen a los niños la homosexualidad, transexualidad y actividades sexuales, y que como padres de familia no se puedan oponer; que se cambien las leyes de género, es decir, que los hombres puedan entrar al baño de mujeres y viceversa; que si como padres de familia o tutores se oponen a la ideología de género, sean castigados (Reforma, 2016).

Otras peticiones fueron realizadas a través de la plataforma digital de Citizen Go. También entregaron cartas al presidente del PRI y a las embajadas y consulados de México en Colombia, El Salvador, España, Brasil, Chile, Perú y Estados Unidos. Mendoza comentó en una entrevista con el Grupo Fórmula que "hay más de mil organizaciones y gente [sic] de diversos credos que apoyan al Frente, opuestas a la iniciativa presidencial sobre los matrimonios entre personas del mismo sexo". Señaló que en la marcha del día 11 de septiembre de 2016, hubo una participación muy buena no sólo en la Ciudad de México, sino en Guadalajara, Querétaro y Guanajuato, "todos en una sola voz y en un solo tema que es la familia". Reiteró su rechazo a la unión entre personas del mismo sexo, y estar en contra de una ideología de género, y de "una educación que pase por encima del derecho de los padres de familia" (Rocha, 2016).

La UNPF se suma, pues, a los grupos conservadores mexicanos que se identifican con los sectores más radicales de la Iglesia católica, y también con redes familiares, empresariales y de profesionistas que van más allá de lo estrictamente educativo. En este marco, la UNPF representa uno de los bastiones más enraizados en la tradición católica conservadora, que en el ámbito de la historia contemporánea no tiene parangón con ninguna otra organización. Su permanencia, en estado de constante lucha, le ha dado la voz cantante como representante del sector de la educación confesional ante los medios de comunicación, a pesar de que su postura difiera en cuanto a objetivos de otras organizaciones, también vinculadas a la Iglesia católica, como el PAN, la Asociación Mexicana para la Superación Integral de la Familia (ANCIFEM), Testimonio y Esperanza o Provida.

Para Roberto Blancarte (2011: 26), "salvo que el catolicismo pase a ser religión nacional o que presenciemos la constitución de un Estado confesional, la Iglesia católica y el Estado en México podrán llegar a un acomodo, a un nuevo modus vivendi, pero jamás a la conciliación definitiva". La doctrina social católica no puede transigir con el Estado mexicano, porque éste ha edificado su régimen sobre principios emanados del liberalismo, es decir, la soberanía popular, el individualismo, el laicismo y todas sus consecuencias. De esta forma, parece ser que estamos ante la presencia de una UNPF que seguirá en la lucha frente al Estado, dando la batalla y el apoyo en favor de cualquier iniciativa estatal que la Iglesia católica o la derecha radical juzgue como un atentado a sus principios fundamentales.

A cien años de su fundación, la UNPF pugna por permanecer viva, teniendo como bandera el mantenimiento de los valores educativos católicos tradicionales. Sin embargo, su 
impacto se desdibuja frente a la preocupación de los sectores conservadores y de derecha, cuyo interés y obsesión se dirigen a otros asuntos más vinculados con la defensa de cuestiones relativas al aborto, la sexualidad, la familia y los derechos humanos.

\section{Fuentes}

\section{Documentos}

Unión Nacional de Padres de Familia (UNPF), varias circulares. Colección particular del Padre Faustino Cervantes.

\section{Bibliografía}

Adame Goddard, J. (2007), Análisis y juicio de la ley de sociedades de convivencia para el Distrito Federal en México, Díkaion, México.

Adame Goddard, J. (1992), Las reformas constitucionales en materia de libertad religiosa, Imdosoc, México.

Blancarte, R. (2011), Iglesia y Estado en México: seis décadas de acomodo y de conciliación imposible, Imdosoc, México.

Britton, J. (1976), Educación y radicalismo en México, 1934-1940, SEP, México (SepSetentas).

Ceballos, M. (2005), La cuestión social en México, vol. 2, Las instituciones, Imdosoc/Academia de Investigación Humanística, México.

Ceballos, M. (1991), El catolicismo social, un tercero en discordia: Rerum Novarum, la cuestión social y la movilización de los católicos mexicanos (1891-1911), El Colegio de México, México.

Ceballos, M. (1987), La democracia cristiana en el México liberal: un proyecto alternativo 1867-1929, Imdosoc, México.

Cervantes Ibarrola, F. (1976), Apuntes para la historia del Secretariado Arquidiocesano de Educación, 50 años. s.ed., México.

Christlieb Ibarrola, A. (1962), Monopolio educativo o unidad nacional, Jus, México.

Diario de los debates (1960), Diario de los debates del Congreso Constituyente, 1916-1917, 2 ts., Ediciones de la Comisión Nacional para las celebraciones del 175 aniversario de la Independencia Nacional y el 75 aniversario de la Revolución Mexicana, México.

Diario Oficial de la Federación (1918), DOF, México, 21 de noviembre.

García Alcaraz, G. (1996), "El Centro Jalisco de la Unión Nacional de Padres de Familia (UNPF), 19171965", Revista Mexicana de Investigación Educativa (julio-diciembre), vol. 1, núm. 2, pp. 439-460.

González, C. (1921-1922), La Asociación Católica Nacional de Padres de Familia frente a la impiedad y el ateísmo oficial. La legislación constitucional, revolucionaria sobre enseñanza y la escuela primaria, elemental y superior, Tipografía de Enrique Luna, Guadalajara.

González Ramírez, M. (1960), La revolución social de México, FCE, México.

Latapí, P. (2000), "Laicidad escolar: cinco vertientes de investigación", en R. Blancarte (comp.), Laicidad y valores en un Estado democrático, Secretaría de Gobernación/El Colegio de México, México, pp. 32-52.

Lerdo de Tejada, S. (1874), "Decreto que reglamenta las Leyes de Reforma incorporadas a la Constitución", 14 de diciembre.

Loaeza, S. (1989), "La lutte entre l'Eglise et l'Etat pour des symboles partagés", El Colegio de México, México (ms.).

Olimón Nolasco, M. (2011), Una república laica, Imdosoc, México. 
Pérez Méndez, M.A. (2010), "La Unión Nacional de Padres de familia y la lucha contra el laicismo, 19171940", Instituto de Investigaciones "Dr. José Ma. Luis Mora”, México, tesis de Maestría en Historia Moderna y Contemporánea.

Quirk, R. (1986), The Mexican Revolution and the Catholic Church, 1910 -1929, Greenwood Press, Westport, Conn.

Rius Facius, A. (1963), La juventud católica y la Revolución mexicana, Jus, México.

Rodríguez Jiménez, Rafael Ignacio (en curso), "Los jesuitas en la revolución mexicana", tesis de doctorado, Universidad Iberoamericana, México.

Sánchez Medal, R. (1992), Reformas a la Constitución en materia religiosa, Imdosoc, México.

Torres Septién, V. (1997), La educación privada en México, 1903-1973, El Colegio de México, México.

Vasconcelos, J. (1972), De Robinson a Odiseo, Jus, México.

Villamil, Jenaro (1989), La Jornada, 10 de diciembre.

Recursos electrónicos

Ingro (2016), "Conforman Frente Nacional por la Familia. No votarán por partidos que atenten contra la familia", Inqro, secc. "Actual, Querétaro", documento html disponible en: <http://www.inqro.com. mx/2016/05/25/conforman-frente-nacional-por-la-familia-no-votaran-por-partidos-que-atentencontra-la-familia/> (fecha de consulta: 8/02/2016).

Barranco, Bernardo (2016), "Entrevista con José Cárdenas. Estado laico mexicano con problemas de debilitamiento", 7 de agosto, documento html disponible en: <http://www.inqro.com. mx/2016/05/25/conforman-frente-nacional-por-la-familia-no-votaran-por-partidos-que-atentencontra-la-familia/> (fecha de consulta: 9/02/2016).

Cruz, A. y Claudia Herrera (2005), "Demandarán a dirigente de la UNPF y a miembro de Provida por discriminación", La Jornada, 9 de febrero, secc. "Sociedad y justicia", documento html disponible en: <http://www.jornada.unam.mx/2005/02/09/index.php?section=sociedad\&article=052nlsc> (fecha de consulta: 9/02/2016).

Frente Nacional por la Familia (2016), portal electrónico disponible en: <http://frentenacional.mx/ quienessomos/> (fecha de consulta: 8/02/2016).

Rocha, Ricardo (2016), "Más de mil organizaciones participaron en marcha: Frente Nacional por la Familia", Radio Fórmula, 12 de septiembre, documento html disponible en: <http://www.radioformula.com.mx/notas.asp?ldn=625389\&idFC=2016> (consulta: 8/02/2017).

Reforma (2016), "Piden modelo educativo sin ideologías", Reforma, 16 de junio, documento html disponible en: <http://www.reforma.com/aplicacioneslibre/preacceso/articulo/default.aspx?id=871600\& $v=4 \&$ impresion $=1>$ [consulta: 9/02/2016).

Ulloa, Paul J. (2015), "Se conforma Frente Ciudadano por la Familia Natural", El Puma BCS, 13 de julio, documento html disponible en: <https://www.elpumabcs.com/2015/07/se-conforma-frenteciudadano-por-la-familia-natural/> (consulta: 9/02/2016).

Valentina Torres Septién es Doctora en Historia por la Universidad Iberoamericana. Sus líneas de investigación se enfocan al estudio de la Historia de la educación en el siglo Xx, la historia cultural femenina en México en el siglo xx, así como la historia de la Iglesia en el siglo xx. Entre sus publicaciones más recientes destaca "Estado contra Iglesia/Iglesia contra Estado. Los libros de texto gratuito: ¿un caso de autoritarismo gubernamental, 1959-1962?", Historia y Grafía (México, Departamento de Historia, Universidad Iberoamericana, 2011); 
"Una idea de patria en la educación católica a través de los libros de texto. De la independencia a la etapa cardenista", en Dimensión religiosa de los conflictos políticos (2019, en prensa), División de Ciencias y Humanidades, UAm/Conacyt, México.

Recibido: 29 de junio de 2018

Aceptado: 20 de septiembre de 2018 